\title{
Classroom Variables and Access to the General Curriculum for Students With Disabilities
}

JANE H. SOUKUP

MICHAEL L. WEHMEYER

SUSAN M. BASHINSKI

University of Kansas

JAMES A. BOVAIRD

University of Nebraska-Lincoln

ABSTRACT: This study investigated the degree to which students with intellectual and developmental disabilities have access to the general education curriculum and the degree to which such access is related to and predicted by classroom setting and ecological variables. We observed 19 students during science or social studies instruction and collected data with Access CISSAR, a computerbased observation system that uses time sampling observation. The results of the study indicated that accommodations and modifications were provided depending on the amount of time students were educated with their nondisabled peers. Further, one-on-one or independent instructional groupings were better predictors of access than whole-group instruction, as were entire or divided group physical arrangements.

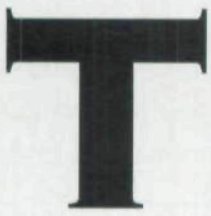

he 1997 amendments to the Individuals With Disabilities Education Act included language requiring the individualized education program (IEP) of any student receiving special education services to describe how the student would be involved with and progress in the general curriculum. The 2004 IDEA amendments (Individuals With Disabilities Education Improvement Act, IDEA, 2004) maintained and extended these "access to the general education curriculum" mandates. In general, IDEA requires that the IEPs of all students receiving special education services - including stu- dents with severe disabilities - identify specific accommodations and curriculum modifications to ensure student involvement with and progress in the general education curriculum.

To date, there is little information about the degree to which accommodations and curriculum modifications are provided to students with severe disabilities or about teacher, student, and classroom ecological variables that may contribute to greater access for this population. Although several models conceptualize how to promote access to the general education curriculum for students with disabilities (see Nolet \& McLaughlin, 2000), only a few (Dymond \& 
Orelove, 2001; Ford, Davern, \& Schnorr, 2001; Janney \& Snell, 2004; Wehmeyer, Lance, \& Bashinski, 2002) explicitly address the needs of students with severe disabilities.

Further, research suggests that the meaning of "access to the general education curriculum" is often not well understood, and few school districts have clear policies regarding how to promote such access (Agran, Alper, \& Wehmeyer, 2002). As a result, practitioners often interpret promoting "access to the general education curriculum" to mean different things. Frequently it is interpreted simply as synonymous with student placement in the general education classroom. The primary focus of the IDEA mandates to ensure student involvement with and progress in the general education curriculum is, however, on what students are taught, how curriculum content is delivered, and what supports are provided to ensure student progress in the general education curriculum, with the "progress" essentially being defined by content and student performance standards in each state. We note this not to negate the importance of inclusive practices for students with disabilities, but instead to observe that a focus on student access to the general education curriculum should, in fact, move the inclusion discussion from being primarily about where students are educated and how to support students in that environment to a discussion about what is taught, how curriculum content is delivered, and what supports are needed to ensure progress in the general education curriculum.

... practitioners often interpret promoting "access to the general education curriculum" to mean different things. Frequently it is interpreted simply as synonymous with student placement in the general education classroom.

Of particular importance for students with severe disabilities are the nature and intensity of supplementary aids and services provided to ensure involvement and progress. Supplementary aids and services are "aids, services, and other supports provided in regular education classes or other education-related settings to enable children with disabilities to be educated with nondisabled children to the maximum extent appropriate" (IDEA, 2004, Sec. 602(33)). Turnbull, Turnbull, and Wehmeyer (2007) suggested a framework for conceptualizing the types of supports intended as supplementary aids and services: curriculum modifications, including curriculum adaptations and curriculum augmentations; modifications to the physical structure of the campus or classroom; modifications to classroom ecological variables; access to educational and assistive technology; assessment and task accommodations; and the availability of paraeducator or peer supports.

Curriculum adaptations refer to modifications that change the way content is represented or presented to students to promote student engagement, either through pedagogical means (e.g., advance organizers) or through the use of technology (e.g., digital talking books). Curriculum augmentations refer to the addition of content to the general education curriculum to enable students to learn skills and strategies to perform more effectively in the general education curriculum (e.g., teaching students learning to learn strategies, cognitive strategies, and student-directed learning strategies).

There are only a limited number of studies of the degree to which students with disabilities are involved with the general education curriculum. This is in part because for many students with disabilities, particularly students with learning disabilities, the focus of the special education services provided has, historically, been to ensure student progress in core content areas. As such, there are not studies that speak explicitly to the degree to which students with learning disabilities are "involved with" the general education curriculum; many studies describe instructional methods and curriculum adaptations and augmentationsshadowing, verbatim notes, graphic or advance organizers, self-regulation strategies, semantic maps, mnemonics, chunking, questioning, and visualizing strategies - to promote progress in core content areas for students with learning disabilities (Baker, Gersten, \& Scanlon, 2002; Graham \& Harris, 2005; Jitendra, Edwards, Choutka, \& Treadway, 2002; Pressley, 2005).

A review of instructional approaches with this population indicates that when curriculum 
modifications such as augmentations (e.g., teaching students cognitive strategies) are used, student engagement and progress improves (De La Paz \& MacArthur, 2003). Cobb-Morocco (2001) concluded that students with learning disabilities can improve their understanding of ideas and concepts, investigative methods, and purposes of knowledge through subject-specific cognitive strategies. Deshler et al. (2001) described validated practices for teaching students with learning disabilities that have positive effects on student learning, including using content enhancement routines that rely on teachers to select critical elements of the content they believe is most important.

\section{... for many students with disabilities, particularly students with learning disabilities, the focus of the special education services provided has, historically, been to ensure student progress in core content areas.}

Swanson and Hoskyn (2001) conducted a component and composite analysis of educational practices to determine which positively influenced the performance of students with learning disabilities. They found that advanced organizers (defined as curriculum adaptations that direct student focus on information that is particularly salient or important in a reading) were successful. Swanson and Deshler (2003) noted that providing educators with specific examples of how to improve upon high quality instructional strategies such as explicit practice by combining them with content enhancement routines or learning-strategy instruction is also critical to improving outcomes for students with disabilities.

Pugach and Warger (2001) observed that the access mandates shift the focus of the "problem" to be solved when teaching students with disabilities from fixing or changing the student to examining the relationship between the student and the curriculum and, when necessary, modifying the curriculum to enable student learning. This perspective is consistent with emerging functional conceptualizations of disability that emphasize the fit between the person's capacities (and limitations) and the context in which that person must function (Wehmeyer, 2003). This is obviously important for students with more severe disabilities; unfortunately, their IEPs often describe an alternative curriculum focused solely on life skills outcomes, with any focus on academic content within these functional contexts.

Lee et al. (2006) reviewed the extant literature relevant to curriculum adaptations and augmentations validated for students with intellectual and developmental disabilities (moderate to severe mental retardation, autism, severe multiple disabilities). They found only a handful of dated studies examining the use of advanced or graphic organizers with students with severe disabilities, and no studies applying strategies such as chunking or mnemonics. Alternatively, there are many studies examining the implementation of student self-directed learning strategies (e.g., self-regulation and self-management strategies) with students with severe disabilities, but few of these have been applied to core academic content areas. One of the effects of the IDEA access mandates has been to spur a focus on the "what is being taught?" question for students with severe disabilities, and researchers are now looking at the role of curriculum adaptations and augmentations to promote progress in areas such as literacy, writing, math, science, and social studies.

The focus of instruction for students with severe disabilities has historically been on functional content often outside the context of the general education curriculum. The assumption that students already have access to that curriculum - as, for the most part, do students with high incidence disabilities - is not valid. Wehmeyer, Lattin, Lapp-Rincker, and Agran (2003) conducted an observational study of middle school students with mental retardation using a time-sample observation method. Each student was observed in classroom contexts for at least eight 15-min observation sessions. The mean observation duration per student was $202 \mathrm{~min}$; the study included a total of $110 \mathrm{hr}$ of observations. The team recorded data on the occurrence or nonoccurrence of variables identified as providing information with regard to student access to the general education curriculum. These included (a) all students in class (including the target student) work- 
ing on tasks associated with same grade level standards; (b) the target student working on standards identified for grade level other than the student's current grade; (c) no students in the class (including the target student) working on tasks associated with district standards or benchmarks; (d) the target student working on tasks linked to IEP goals or objectives; (e) the target student receiving any accommodations; (f) the target student working on adapted tasks or activities; and (g) the target student working on tasks or activities that augmented the curriculum.

During $70 \%$ of the intervals, students with mental retardation were engaged in a task related to a school district standard. This varied, however, by level of disability. Students with mild cognitive impairments were engaged in a task linked to a standard in $87 \%$ of intervals; students with more severe intellectual impairments were doing so during only $55 \%$ of intervals. Further, students educated in the general education classroom were observed working on tasks linked to a standard in $90 \%$ of intervals, whereas students served primarily in self-contained settings engaged in tasks related to a standard in only $50 \%$ of the observation intervals.

Overall, students were provided accommodations to work on a task linked to a standard 5\% of the time, were working on an adapted task 3\% of the time, and were being taught strategies to improve their capacity to engage with the general education curriculum (i.e., curriculum augmentations) only $0.15 \%$ of the time. The researchers observed significant differences by setting (general education classroom or self-contained classroom) in a number of areas. Students educated in the general education classroom were significantly more likely to be working on a task linked to a standard, in general, and to be working on an adapted task. Students educated primarily in selfcontained settings were significantly more likely to be working on a task linked to a standard below grade level or on a task not linked to a standard, and to be working on a task linked to an IEP objective.

The Wehmeyer et al. (2003) study suggests that classroom setting and ecological variables are important in understanding how to promote access to the general education curriculum. In addition to classroom setting (general vs. self- contained classroom), classroom ecological variables such as instructional grouping strategies and classroom physical arrangements are relevant to examine. Instructional grouping refers to the student grouping formations in which teachers present the curriculum. Teachers may have students work with content as a whole class, in small groups, independently, or one-on-one with another adult. There are a number of studies that show that some classroom variables, particularly one-on-one and small group teaching arrangements, support learning for students with disabilities more effectively than does whole-group instructional arrangements (Bulgren \& Carta, 1993; Greenwood, Carta, Kamps, \& ArreagaMayer, 1990; Kamps, Leonard, Dugan, Boland, \& Greenwood, 1991; Thurlow, Ysseldyke, Graden, \& Algozzine, 1983).

Logan, Bakeman, and Keefe (1997) examined instructional grouping as it impacted the education of students with moderate to severe disabilities. They found that instruction using whole-group arrangements for students with disabilities was most frequent ( $43 \%$ of observation intervals), followed by one-on-one instructional grouping (29\%), small group instructional grouping $(16 \%)$, and independent grouping (13\%). When, however, these researchers examined student engagement in learning (e.g., writing, task participation, reading aloud, reading silently, talking about academic content or issues, and playing appropriately) as a function of instructional grouping, they found that students in the wholeclass instructional grouping condition were engaged for only $23 \%$ of time observed, compared to students in one-on-one, small group, and independent work conditions, who were coded as engaged for $43 \%, 42 \%$, and $50 \%$ of the observation intervals, respectively.

Physical classroom arrangement is another ecological variable that might impact access. Greenwood et al. (1997) defined physical classroom arrangement as "determined by the actual location of students in the classroom in relationship to each other" (p. 92). They also identified three possible physical arrangements: entire group, divided group, and individual group. There is a limited research base regarding the impact of physical classroom arrangement on educational outcomes. Hunt, Farron-Davis, Beckstead, 
Curtis, and Goetz (1994) compared 16 students who were fully included in the general education classroom with 16 students in self-contained special education classrooms. One of their findings was that students receiving special services were grouped more often with peers (i.e., entire group or divided group physical classroom arrangement) in the general education classroom than students receiving services in the special education classroom. The latter group was observed as being alone more often (i.e., individual physical classroom arrangement). However, the Hunt et al. study did not investigate the impact of physical arrangement on engagement levels. Physical arrangement, like instructional groupings, may be associated with higher levels of academically focused engagement but at this point there is not enough research regarding the effects of different physical classroom arrangements to make this assumption.

As noted previously, Wehmeyer et al. (2003) found that students receiving their education in general education settings had greater access to the general education curriculum. Similarly, Logan and Keefe (1997) found that students with severe disabilities educated in general education classrooms received more academically focused instruction than students with severe disabilities who were educated in self-contained classrooms. Students educated in self-contained classrooms participated more in functional activities than curriculum driven content. Both studies suggest that students with severe disabilities who are educated in general education classrooms may have greater access to the general education curriculum than those educated in self-contained settings.

The purpose of the current study was to replicate and extend findings from Wehmeyer et al. (2003) by measuring variables related to access to the general education curriculum via a computer-based data collection system that allowed for the collection of a greater range of variables pertaining to supplementary aids and services, including curriculum modifications, educational and assistive technology, adult and peer supports, and classroom ecological variables. The study examined three research questions:
- To what degree do students with developmental and intellectual disabilities have access to the general education curriculum?

- Do inclusion status, classroom setting, and classroom ecological variables correlate to access to the general education curriculum for students with developmental and intellectual disabilities?

- What instructional groupings, physical classroom arrangements, and classroom setting conditions predict higher levels of student access to the general education curriculum?

\section{METHOD}

\section{SAMPLE}

The 19 participants were elementary students with mental retardation $(n=17)$ or autism $(n=2)$ from three suburban school districts in the Midwest. Students ranged in age from 7 to 12 years $($ mean $=10.63$ years, $S D=1.34)$ and were enrolled in Grades 2 through 6. Twelve students were male (mean age $=10.67, S D=1.50$ ); seven students were female (mean age $=10.57, S D=$ 1.13). Fifteen students (79\%) were Caucasian, two students $(10 \%)$ were Asian/Pacific Islander, one student was African American (5\%), and one student was Hispanic American (5\%).

Participants were recruited by contacting district personnel to obtain permission to conduct the study. Once permission was obtained, the lead researcher contacted the special education coordinator in each district and met to discuss the study and determine if the district had any students who met the study criteria (i.e., kindergarten through sixth grade with mental retardation or autism receiving science or social studies instruction). If so, the special education coordinator provided contact information for each student's special education teacher. The researcher then contacted each teacher, explained the study, and provided them with consent forms to send to parents or guardians of prospective study participants. All students for whom informed consent was obtained were included in the study. All special education teachers in the study were fully licensed to teach students with mental retardation or autism in the state. 
Level of Support Need. Current (i.e., within 2 years) scores from standardized intelligence tests were not available for most students. To provide an indicator of student level of functioning, teachers responded to two items asking them to rate, on a Likert-type scale ranging from 1 (no supports needed) to 5 (full physical prompts needed), the degree to which students needed supports to function overall (e.g., independent living, daily care, community integration), referred subsequently to as overall support needs, and to acquire new knowledge and skills, referred subsequently to as learning support needs.

Inclusion Status. The measurement system described in the Instrumentation subsection provided a within-student indicator of classroom setting. In addition, however, we were interested in obtaining between-student estimates of the impact of classroom setting. The percentage of the school day in which students were educated in the general education classroom, on a daily basis, was determined by interviewing the student's special education teacher. The total percentage of the school day spent in the general education classroom ranged from $0 \%$ to $100 \%$. These data clustered naturally into three levels of time spent in the general education classroom: low, medium, and high. These groupings (high inclusion, medium inclusion, and low inclusion) were used for analyses pertaining to classroom setting. Students in the high inclusion group ( $n=6$, mean age $=10.83)$ spent between $75 \%$ and $100 \%$ of their school days in the general education classroom. Students in the medium inclusion group ( $n$ $=7$, mean age $=10.71$ ) spent between $51 \%$ and $75 \%$ of their days in the general education classroom, and students in the low inclusion group ( $n$ $=6$, mean age $=10.33$ ) spent between $0 \%$ and $50 \%$ of their days in the general education classroom. Respectively, the average overall support needs ratings for students in the high, medium, and low inclusion groups were $3.67,3.71$, and 3.33 , respectively. The average learning support needs ratings for students in the high, medium and low inclusion groups were 4.00, 4.43, and 4.33 .

\section{INSTRUMENTATION}

Measuring Access to the General Education Curriculum: We collected data regarding student access to the general education curriculum with a Windows-based time sampling data collection system. Access CISSAR (Bashinski \& Wehmeyer, 2002) is an expanded version of a direct observational system, the MainStream Version of the Code for Instructional Structure and Student Academic Response (MS-CISSAR; Carta, Greenwood, Schulte, Arreaga-Mayer, \& Terry, 1988).

MS-CISSAR focuses on an individual student as an observer's target and, using a momentary time-sampling methodology, structures the collection of data on 105 individual codes in 13 categories of variables, across 3 conceptual groupings: classroom ecology (5 categories), teacher behavior ( 5 categories), and student behavior (3 categories). Data are collected in each of the 13 categories of variables during a 60 -sec cycle composed of 20-sec observation intervals. One event may be recorded for each of the 13 categories during each cycle, and data entry is limited to four active keys to reduce the probability of erroneous entries. Length of data collection sessions using MS-CISSAR is flexible and may be structured, in full-minute increments, as a researcher deems appropriate.

MS-CISSAR was subjected to rigorous technical scrutiny during its development and fieldtesting. Test-retest reliabilities averaged .85 overall (Greenwood et al., 1997). MS-CISSAR's divergent validity was demonstrated through the correlation of students' higher levels of academic responding in the classroom with posttest gains on the Metropolitan Achievement Test-Basic Scale (Greenwood, Arreaga-Mayer, \& Carta, 1994). Additionally, Kamps, Greenwood, and Leonard (1991) documented treatment validity in an investigation with students with autism. MSCISSAR has been employed successfully in a number of research studies related to effectiveness in classroom settings (Greenwood, Carta, Arreaga-Mayer, \& Rager, 1991; Kamps, Greenwood et al.; Logan et al., 1997; Logan \& Keefe, 1997).

Bashinski and Wehmeyer (2002) expanded MS-CISSAR to collect additional data regarding when and how opportunities were made available for students to access the general education cur- 
Access CISSAR Toggle Number, Description, and Frequency of Intervals Observed

\begin{tabular}{|c|c|c|c|c|}
\hline Toggle \# & Toggle Description & $\mathrm{N}$ & Sum & $\%$ \\
\hline $\mathrm{F} 2$ & Peers - any general ed standard & 1140 & 162 & 14.2 \\
\hline F3 & Peers - grade level standard & 1140 & 765 & 67.1 \\
\hline F4 & Participant - any general ed standard & 1140 & 229 & 20.1 \\
\hline F5 & Participant - grade level standard & 1140 & 691 & 60.6 \\
\hline F6 & Participant - IEP objectives & 1140 & 266 & 23.3 \\
\hline F7 & $\begin{array}{l}\text { Accommodations (at least one of the following) } \\
1 \text { - Paraprofessional } \\
2 \text { - Peer support } \\
3 \text { - Note-taker } \\
4 \text { - Environmental adjustment } \\
5 \text { - Extended time } \\
6 \text { - Redistributed time } \\
7 \text { - Assistive technology } \\
8 \text { - Other }\end{array}$ & $\begin{array}{l}1140 \\
1140 \\
1140 \\
1140 \\
1140 \\
1140 \\
1140 \\
1140 \\
1140\end{array}$ & $\begin{array}{r}768 \\
745 \\
11 \\
31 \\
0 \\
0 \\
0 \\
3 \\
0\end{array}$ & $\begin{array}{r}67.4 \\
65.4 \\
1.0 \\
2.7 \\
0.0 \\
0.0 \\
0.0 \\
0.3 \\
0.0\end{array}$ \\
\hline F8 & $\begin{array}{l}\text { Augmentations (at least one of the following) } \\
1 \text { - Strategies for learning } \\
2 \text { - Strategies for test-taking } \\
3 \text { - Strategies for organization } \\
4 \text { - Strategies for self-regulation } \\
5 \text { - Other }\end{array}$ & $\begin{array}{l}1140 \\
1140 \\
1140 \\
1140 \\
1140 \\
1140\end{array}$ & $\begin{array}{l}0 \\
0 \\
0 \\
0 \\
0 \\
0\end{array}$ & $\begin{array}{l}0.0 \\
0.0 \\
0.0 \\
0.0 \\
0.0 \\
0.0\end{array}$ \\
\hline F9 & $\begin{array}{l}\text { Adaptations (at least one of the following) } \\
1 \text { - Adjusted reading demand } \\
2 \text { - Adjusted cognitive demand (not reading) } \\
3 \text { - Nonprint content } \\
4 \text { - Content through technology } \\
5 \text { - Enhanced content } \\
6 \text { - Nontraditional response(s) to instruction } \\
7 \text { - Nontraditional instructional materials } \\
8 \text { - Other }\end{array}$ & $\begin{array}{l}1140 \\
1140 \\
1140 \\
1140 \\
1140 \\
1140 \\
1140 \\
1140 \\
1140\end{array}$ & $\begin{array}{r}201 \\
71 \\
96 \\
88 \\
0 \\
7 \\
0 \\
0 \\
0\end{array}$ & $\begin{array}{r}17.6 \\
6.2 \\
8.4 \\
7.7 \\
0.0 \\
0.6 \\
0.0 \\
0.0 \\
0.0\end{array}$ \\
\hline
\end{tabular}

riculum. This expanded version, Access CISSAR, includes all 13 of the original classroom ecology, teacher behavior, and student behavior categories from MS-CISSAR, and 102 of the original 105 variables (three codes were eliminated from the teacher behavior category). In addition to the original MS-CISSAR variables, Access CISSAR was designed to capture data indicating the degree to which students had access to the general education curriculum. The observational categories were derived from the model for access proposed by Wehmeyer et al. (2002) and codes developed by Wehmeyer et al. (2003). The final categories were (a) whether a participant (e.g., the student with a disability being observed) was engaged in a task linked to any general education standard; (b) whether a participant was engaged in a task linked to a grade level standard; (c) whether a participant's peers were engaged in a task linked to any general education standard; (d) whether a participant's peers were engaged in a task linked to a grade level standard; (e) whether a participant was engaged in a task linked to an IEP goal; ( $f$ ) whether accommodations were in place to support the student; (g) whether curriculum adaptations were provided; and $(\mathrm{h})$ whether curriculum augmentations were observed. In Access CISSAR, each of these behaviors or activities was linked to a "virtual toggle switch" correlating to the computer keys F2 through F9 (see Table 1). Each 
toggle was set at "off" or "on" before the start of each observation. For intervals in which a toggle was on, the variable was counted as present. Toggles could be switched on or off at any time during the observation if any aspect of the situation changed, and the entire cycle in which a change was made reflected such.

In addition, if during the observation period any accommodations were observed (including supplementary aids and services, curriculum adaptations, or curriculum augmentations), the observer selected from among subcategories to describe the specific type(s) of accommodation or curriculum modifications provided to the student. There were eight additional coding variables further describing the accommodation(s), five describing curriculum augmentations, and eight variables describing curriculum adaptations (see Table 1). All Access CISSAR variables could be reentered or changed at any time during data collection. The observer could simultaneously code as many access-related variables as were observed.

\section{PROCEDURES}

After parental consent was obtained, we interviewed each student's special education teacher to collect information about the student. During these interviews, we reviewed each student's IEP to record information for use during classroom observations. The lead researcher, who was the primary data collector, received one-on-one training from one of the developers of Access CISSAR, who in turn had been trained to mastery on MSCISSAR. Training began with an "instrument calibration" process, a test of the observer's capacity to collect data from a videotaped classroom simulation in agreement with a standard set by the original MS-CISSAR software developers. Reliability training for the MS-CISSAR also included in-school practice and reliability sessions.

After receiving an overall reliability rating of $97 \%$ agreement for three 15 -min in-school training sessions on the MS-CISSAR, the primary observer received training on Access CISSAR, obtaining a reliability score of $97 \%$ for that version. Overall, the primary observer received 33.75 hours of training in the MS-CISSAR and Access CISSAR systems.

\section{RELIABILITY CODER TRAINING}

Another member of the research team was also trained to mastery using Access CISSAR, and served as a reliability coder. Total training time for the reliability coder was 32 hours for MS-CISSAR and Access CISSAR. The reliability coder received an overall reliability score of $93 \%$ for three 15 -min in-school training sessions on Access CISSAR.

\section{DATA COLLECTION}

We observed students during core academic instructional time in science or social studies for three 20-min intervals each, and collected interrater reliability for each of the 19 students for one of the three data collection sessions. Data collection began and was completed within a 3-month period in the spring semester of the school year. Immediately before each data collection session, the researcher (and reliability coder, if scheduled) met with the teacher to clarify what content-related standards were to be addressed by that day's lesson; whether tasks were linked to grade level or off-grade level content standards; whether tasks were linked to an IEP goal or objective; and what types of accommodations, curriculum adaptations, or augmentations were typically used with the student.

During each session, the observer was seated to record data where she was able to hear and see a study participant, but not intrude on instructional activities. The observer entered student information required by Access CISSAR and coded the initial Access toggle settings before beginning the coding cycle. The observer began the formal coding session by entering information that corresponded to the situation observed using the MSCISSAR protocol "look, record, and rest" pattern. All students were observed continuously for 20 min for a combined observation time of $60 \mathrm{~min}$ per student. This resulted in coding 180,20 -sec intervals per student and 1140 total minutes of observations across all students.

The Access CISSAR data collection options pertaining to instructional grouping were whole class, small group, one-on-one, and independent. Physical arrangement options included entire group, divided group, and individual group. In addition to the teacher-generated levels of inclu- 
sion, Access CISSAR recorded whether the observation interval occurred in the general education classroom, a self-contained classroom, a resource room, the library, music room, art room, therapy room, hall, auditorium, or other.

\section{DATA ANALYSIS}

We conducted interrater agreement checks for $33 \%$ of total data sessions for a total of 378 observation minutes. Following data collection, the researcher ran the MS-CISSAR reliability check report. The MS-CISSAR reliability check report was modified to include the supplemental variables of the Access CISSAR instrument and determine the reliability of the Access CISSAR's additional variables. We used Cohen's Kappa (Sax, 1997) to compute an index of interrater agreement; Kappa values higher than Kappa $=.60$ are generally considered to be adequate levels of agreement (Hartmann \& Woods, 1982).

We first depicted data from each of the Access toggles (F2-F9) in tabular format across the access and classroom ecological variables. We conducted analyses of variance by gender and inclusion group to determine if there were any differences among participants based on overall and learning support need ratings.

Access Score. For purposes of addressing research questions 2 and 3 , we calculated an overall access score by combining assigned point values for the F4 toggle (participant engaged in task linked to any general education standard) or F5 toggle (participant engaged in task linked to grade level standard), plus F7 (accommodations), F8 (curriculum augmentations), and F9 (curriculum adaptations):

$$
\text { Access }=\left\{\begin{array}{cl}
(1 \cdot \mathrm{F} 4)+(1 \cdot \mathrm{F} 7)+(3 \cdot \mathrm{F} 8)+(3 \cdot \mathrm{F} 9 & \text { if } \mathrm{F} 4=1 \\
(3 \cdot \mathrm{F} 5)+(1 \cdot \mathrm{F} 7)+(3 \cdot \mathrm{F} 8)+(3 \cdot \mathrm{F} 9) & \text { if } \mathrm{F} 5=1 \\
0 & \text { if } \mathrm{F} 4=\mathrm{F} 5=0
\end{array}\right.
$$

During each observation, each minute the $\mathrm{F} 4$ (i.e., any general education standard) toggle was activated counted as one point. If the F5 (i.e., grade level general education) toggle was activated, three points were tallied for the total access score. When any F7 (i.e., accommodation) was coded during an observation interval concurrently with either F4 or F5 (i.e., any standard or grade level standard), one point was counted toward the total access score. In any interval in which an F8 (curriculum augmentation) or F9 (curriculum adaptation) were coded concurrently with F4 or $\mathrm{F} 5$, three points were added to the total access score. Thus, the resulting access score for any given observation interval per student could range between 0 and 10 .

The weighted value for each variable was based on the hypothesized importance of that variable, as determined by the investigators, for students with severe disabilities to achieve access to the general education curriculum. In essence, the "gold standard" for access should be that students are working on grade-level general education standards (F5) and receive needed accommodations and curriculum modifications (F7-F9). The weighting system differentiates between circumstances in which students were receiving instruction and curriculum modifications that met or approached this "gold standard" and circumstances when only one component was in place (e.g., only paraprofessional support).

Analysis Plan. The impacts of inclusion group, instructional grouping, physical classroom arrangement, and classroom setting conditions on access were analyzed as multilevel models (MLM; Raudenbush \& Bryk, 2002; Snijders \& Bosker, $1999)$ with the 60 multiple observations (cycles) nested within student. This was accomplished by using a general linear mixed model implemented through SAS/STAT 9.1. Final parameter estimates for both fixed and random effects were obtained through maximum likelihood estimation using the Satterthwaite method (Satterthwaite, 1946) for determining the denominator degrees of freedom.

All tests of fixed effects were two-tailed hypothesis tests with the overall access score as the outcome measure predicted by (a) inclusion group, (b) instructional grouping, (c) physical classroom arrangement, (d) classroom setting conditions, and (e) wave of observation. Instructional grouping, physical classroom arrangement, and classroom setting changed from cycle to cycle and were thus treated as cycle-level (Level 1) predictors of access to the curriculum. Inclusion group was included as a student-level (Level 2) predictor of access as it was considered a static characteristic of each student. The repeated observations/cycles were collected to maximize the reli- 
ability of the observations and not in anticipation of any particular growth or change process; the wave of observation (incremented sequentially by cycle 1-60) was included as a cycle-varying (Level 1) covariate to account for possible trends that might occur over the course of the 60 observations. The fixed effect of wave then reflects the average (across all 19 participants) change in access over the 60 cycles. The actual metric for wave was 0 to 59 so that the intercept could be interpreted as the level of access at the beginning of the first observation period. Although observations were obtained over three sessions of 20 cycles each, preliminary analyses showed no impact of session on the outcome variable, so session was not included in any subsequent analyses. Due to the small number of students and degrees of freedom available for model testing, we did not test higher order interaction terms.

We chose MLM as the analysis paradigm over other procedures appropriate for repeated measures data because it allows for modeling of individual differences (i.e., random effects) in what occurs over the repeated measures. The random effects portion of all models featured an unstructured between-subjects covariance matrix with a random intercept variance $\left(\sigma_{h t}^{2}\right)$, a random slope variance for wave $\left(\sigma_{\text {Wave }}^{2}\right)$, and a covariance between intercept and wave $\left(\sigma_{\text {Int }}\right.$ Wave $)$. The withinsubjects error covariance matrix was modeled with an independence structure, resulting in a single residual error variance. The random intercept is interpreted as the between-subjects variability in the level of access at the first wave of observation, and the random slope is the between-subjects variability in the change in access that occurs over the duration of the 60 observation waves. The covariance is the relationship between a student's level of access at the first wave and the rate of change in access over the course of observation. Finally, the within-subjects error is the average misfit of the model at any given wave. The fixed effect for wave was expected to be nonsignificant, but it is conceivable that some individuals will experience an increase in access and others experience a decrease in access over the course of the study. This would result in a significant random slope for wave due to the individual differences in observed trend.
Pseudo- $R^{2}$ statistics representing the proportional reduction in error (Snijders \& Bosker, 1999) are reported for within-students variance $\left(R_{1}^{2}\right)$ and between-students variance $\left(R_{2}^{2}\right)$ for all $F$-tests involving predictors of interest. We conducted follow-up mean comparisons for all significant main effects using a Tukey multiplicity correction within PROC MIXED, and report the standardized effect size, $\delta$ (Moerbeek, Van Breukelen, Berger, \& Ausems, 2003; Raudenbush, Spybrook, Liu, \& Congdon, 2005), for all follow-up tests.

\section{RES U L T S}

\section{INTERRATER RELIABILITY}

The average Cohen's Kappa for observations across all study participants was .94 , ranging from .85 to .99 . For 16 of the 19 students, interrater reliability was calculated based on 20 observation cycles, with 21 cycles for 2 participants, and 18 cycles for 1 participant.

\section{ACCESS TO THE GENERAL EDUCATION CURRICULUM}

There were no significant differences by gender on overall $F(1,18)=1.88, p=.19$ or learning $F(1,18)=.01, p=.91$ support need ratings, nor were there differences on overall, $F(2,17)=.53, p$ $=.59$, or learning support need ratings among the three inclusion groups, $F(2,17)=.723, p=.50$. Table 2 summarizes findings that describe the degrees to which study participants had access to the general education curriculum. The analysis indicated that the F3 toggle (peers working on grade level standard) was activated in $67 \%$ of the intervals. Similarly, the F5 toggle (participant on grade level standard) was activated $61 \%$ of intervals. The F2 toggle (peers on any standard) was coded $14 \%$ of intervals; the F4 toggle (participant on any standard) was observed in $20 \%$ of intervals. The F6 toggle (participant working on IEP objective) was coded $23 \%$ of intervals. No curriculum augmentations (F8) were coded. At least one type of an accommodation (F7) was coded in $67 \%$ of intervals; participants were coded using at least one type of curriculum adaptation (F9) $18 \%$ of time observed. When an accommodation oc- 


\begin{tabular}{|c|c|c|c|c|c|}
\hline \multirow[b]{2}{*}{ Toggle \# } & \multirow[b]{2}{*}{ Toggle Description } & \multirow[b]{2}{*}{ Mean } & \multirow[b]{2}{*}{ SD } & \multicolumn{2}{|c|}{$95 \% C I$} \\
\hline & & & & Lower & Upper \\
\hline \multicolumn{6}{|c|}{ High Inclusion $(N=6)$} \\
\hline F2 & Peers - any gen ed standard & 4.44 & 10.89 & 0.00 & 13.33 \\
\hline F3 & Peers - grade level standard & 95.56 & 10.89 & 86.67 & 100.00 \\
\hline F4 & Participant - any gen ed standard & 14.17 & 20.78 & 1.39 & 31.11 \\
\hline F5 & Participant - grade level standard & 83.33 & 19.61 & 67.78 & 95.83 \\
\hline F6 & Participant - IEP objectives & 9.72 & 11.28 & 2.22 & 18.06 \\
\hline F7 & Accommodations & 78.33 & 19.78 & 63.33 & 91.94 \\
\hline F8 & Augmentations & 0.00 & 0.00 & 0.00 & 0.00 \\
\hline F9 & Adaptations & 17.50 & 13.85 & 7.78 & 27.50 \\
\hline \multicolumn{6}{|c|}{ Medium Inclusion $(N=7)$} \\
\hline F2 & Peers - any gen ed standard & 0.00 & 0.00 & 0.00 & 0.00 \\
\hline F3 & Peers - grade level standard & 100.00 & 0.00 & 100.00 & 100.00 \\
\hline F4 & Participant - any gen ed standard & 2.86 & 5.67 & 0.00 & 7.14 \\
\hline F5 & Participant - grade level standard & 93.10 & 12.93 & 83.57 & 100.00 \\
\hline F6 & Participant - IEP objectives & 5.71 & 15.12 & 0.00 & 17.14 \\
\hline F7 & Accommodations & 70.48 & 21.01 & 56.43 & 84.76 \\
\hline F8 & Augmentations & 0.00 & 0.00 & 0.00 & 0.00 \\
\hline F9 & Adaptations & 11.90 & 18.82 & 1.19 & 25.71 \\
\hline \multicolumn{6}{|c|}{ Low Inclusion $(N=6)$} \\
\hline F2 & Peers - any gen ed standard & 40.56 & 32.02 & 18.06 & 62.78 \\
\hline F3 & Peers - grade level standard & 0.28 & 0.68 & 0.00 & 0.83 \\
\hline F4 & Participant - any gen ed standard & 46.11 & 25.88 & 25.56 & 62.78 \\
\hline F5 & Participant - grade level standard & 0.00 & 0.00 & 0.00 & 0.00 \\
\hline F6 & Participant - IEP objectives & 57.50 & 41.35 & 28.06 & 86.67 \\
\hline F7 & Accommodations & 52.78 & 45.81 & 20.00 & 86.11 \\
\hline F8 & Augmentations & 0.00 & 0.00 & 0.00 & 0.00 \\
\hline F9 & Adaptations & 24.44 & 38.23 & 0.00 & 51.67 \\
\hline \multicolumn{6}{|c|}{ TOTAL $(N=19)$} \\
\hline F2 & Peers - any gen ed standard & 14.21 & 25.68 & 3.60 & 26.32 \\
\hline F3 & Peers - grade level standard & 67.11 & 47.04 & 46.05 & 88.07 \\
\hline F4 & Participant - any gen ed standard & 20.09 & 25.88 & 9.30 & 31.84 \\
\hline F5 & Participant - grade level standard & 60.61 & 44.38 & 40.96 & 79.47 \\
\hline F6 & Participant - IEP objectives & 23.33 & 34.03 & 9.39 & 39.47 \\
\hline F7 & Accommodations & 67.37 & 30.88 & 53.16 & 80.26 \\
\hline F8 & Augmentations & 0.00 & 0.00 & 0.00 & 0.00 \\
\hline F9 & Adaptations & 17.63 & 24.61 & 7.54 & 29.04 \\
\hline
\end{tabular}

curred, it was primarily the presence of a paraprofessional $(65 \%)$, and observed curricular adaptations were primarily reading demand adjustments $(6 \%)$, nonreading cognitive demand adjustments $(8 \%)$, or the use of nonprint content $(8 \%)$.

Table 2 also presents findings for Access toggle activation by inclusion group. Student participants in the high and medium inclusion groups spent similar percentages of time working on tasks linked to grade level standards (F4; i.e., high inclusion $=83 \%$, medium inclusion $=93 \%$ ). Nondisabled classmates of participants in the high and medium inclusion groups spent similar amounts of time working on grade level standards (i.e., high inclusion $=96 \%$, medium inclusion $=$ $100 \%$ ). Conversely, students in the low inclusion 
group (students educated in the general education setting less than half of the school day), never worked on a task linked to a grade level standard and spent more of their time working on tasks linked to any grade level standards (F4; 46\%). The average percentage of intervals in which students received accommodations (F7) was higher in the high and medium inclusion groups than in the low inclusion group. A somewhat similar proportion of intervals in which a student received a curriculum adaptation was coded for all groups (i.e., high inclusion $=18 \%$, medium inclusion $=$ $12 \%$, and low inclusion $=24 \%$ ).

Participants attained a mean total access score of $3.08(S D=1.94)$. Actual observed access scores ranged from 0 to 7 within a potential range of 0 to 10 . Although there is skewness and kurtosis present in the data, the overall distribution is unimodal and moderately symmetrical. The high inclusion group had the highest mean total access score $(M=3.95, S D=1.55)$, with students in the medium inclusion group next $(M=3.88, S D=$ $1.18)$, and students in the low inclusion group having the lowest mean access score $(M=1.27$, $S D=1.77$ ).

\section{VARIABILITY IN WITHIN-SUBJECT PREDICTORS}

An individual student's instructional grouping, physical classroom arrangement, and classroom setting conditions were all found to vary by varying degrees across the 60 observation cycles. Twenty-six percent of the observed students experienced variability in their classroom settings, $68 \%$ experienced variability in their physical classroom arrangement, and $100 \%$ experienced variability in their instructional groupings between the 601 -min cycles. Students spent an average of $94 \%$ of their time in the same classroom setting, $83 \%$ of their time in the same physical arrangement, and only $60 \%$ of their time in the same instructional grouping over the 60 observation cycles. As a result, the classroom setting variable is almost a static student characteristic, and certainly more so than physical arrangement or instructional grouping. This relationship is reflected in the Satterthwaite denominator degrees of freedom reported for each analysis in Table 3. That is, the less within-subject variability for a predictor, the closer it resembles a between-subject predictor (such as inclusion group), and the closer the denominator degrees of freedom will be to the number of between-subjects units $(N=19)$ than the number of within-subjects observations $(N=1140)$. This supports the use of these three variables as within-subject predictors, while correcting for reduced degrees of within-subjects variability when necessary.

\section{IMPACT OF INCLUSION GROUP STATUS AND ClaSSROOM ECOLOGICAL VARIABLES}

Inclusion Status. Table 3 shows a significant effect for level of inclusion on access, $F(2,16)=$ 20.46, $p<.01, R_{2}^{2}=0.58$ and an expected nonsignificant wave effect, $F(1,18)=3.29, p=0.09$. Follow-up tests, reported in Table 4, indicate that both high inclusion and medium inclusion group members had more access to the general education curriculum than low inclusion group members, but high and medium inclusion participants had equal access to the curriculum (high vs. low: $t(16)=5.57, \operatorname{adj}-p<0.01, \delta=1.66$; medium vs. low: $t(16)=5.58$, adj $-p<0.01, \delta=1.60$; high vs. medium: $t(16)=0.20$, adj-p $=0.98, \delta=0.06$ ).

Instructional Grouping. The results shown in Table 3 suggest no significant effect of instructional grouping on access to the general education curriculum, $F(4,1113)=0.33, p=.86$, thus follow-up mean difference tests were not conducted.

Physical Arrangement. Table 3 shows no significant wave effect, $F(1,17.9)=3.69, p=.07$, but a significant effect of physical arrangement on access to the general education curriculum was demonstrated, $F(2,1073)=20.25, p<0.01, R^{2}{ }_{1}=$ 0.24 . The follow-up mean difference tests in Table 4 indicate that participants in both a divided-group and entire-group physical arrangement had more access to the general education curriculum than study participants in an individual physical arrangement, but divided-group and whole-group participants have essentially equal access to the general education curriculum, divided group vs. individual: $t(1007)=4.92$, adj$p<0.01, \delta=0.50$; entire group vs. individual: $t(1096)=6.33$, adj $-p<0.01, \delta=0.61 ;$ divided group vs. entire group: $t(1095)=-1.44$, adj $-p=$ $0.32, \delta=0.11$. 
TABLE 3

Multilevel Modeling Results for Predicting Access from Level of Inclusion, Instructional Grouping, Physical Arrangement, and Classroom Setting

\begin{tabular}{|c|c|c|c|c|c|c|c|c|}
\hline \multirow[b]{2}{*}{ Fixed Effects } & \multicolumn{4}{|c|}{ Level of Inclusion } & \multicolumn{4}{|c|}{ Instructional Grouping } \\
\hline & Num DF & Den DF & F & Sig. & Num DF & Den DF & $F$ & Sig. \\
\hline Wave & 1 & 18.0 & 3.29 & 0.09 & 1 & 18.0 & 3.53 & 0.08 \\
\hline IV & 2 & 16.0 & 20.46 & $<0.01$ & 4 & 1113.0 & 0.33 & 0.86 \\
\hline Random Effects & $\begin{array}{l}\text { Variance } \\
\text { Estimate }\end{array}$ & & & Sig. & $\begin{array}{l}\text { Variance } \\
\text { Estimate }\end{array}$ & & & Sig. \\
\hline$\sigma_{b h t}^{2}$ & 1.497 & & & $<0.01$ & 3.604 & & & $<0.01$ \\
\hline$\sigma_{\text {Wave }}^{2}$ & 0.001 & & & $<0.01$ & 0.001 & & & $<0.01$ \\
\hline$\sigma_{I n t^{*} \text { Wave }}$ & -0.030 & & & 0.02 & -0.040 & & & 0.03 \\
\hline \multirow[t]{2}{*}{ Residual } & 1.257 & & & $<0.01$ & 1.239 & & & $<0.01$ \\
\hline & \multicolumn{4}{|c|}{ Physical Arrangement } & \multicolumn{4}{|c|}{ Classroom Setting } \\
\hline Fixed Effects & Num DF & Den DF & $F$ & Sig. & Num DF & Den DF & $F$ & Sig. \\
\hline Wave & 1 & 17.9 & 3.69 & 0.07 & 1 & 18.3 & 3.13 & 0.09 \\
\hline $\mathrm{IV}^{*}$ & 2 & 1073.0 & 20.25 & $<0.01$ & 4 & 159.0 & 4.58 & $<0.01$ \\
\hline Random Effects & $\begin{array}{l}\text { Variance } \\
\text { Estimate }\end{array}$ & & & Sig. & $\begin{array}{l}\text { Variance } \\
\text { Estimate }\end{array}$ & & & Sig. \\
\hline$\sigma_{b n t}^{2}$ & 2.454 & & & $<0.01$ & 2.867 & & & 0.01 \\
\hline$\sigma_{\text {Wave }}^{2}$ & 0.001 & & & $<0.01$ & 0.001 & & & $<0.01$ \\
\hline$\sigma_{\text {Int }} *$ Wave & -0.029 & & & 0.04 & -0.039 & & & 0.03 \\
\hline Residual & 1.220 & & & $<0.01$ & 1.248 & & & $<0.01$ \\
\hline
\end{tabular}

Note. IV = the predictor differentiating each quadrant of the table. For example, the test of fixed effect in the upper left corner $(F=20.46)$ refers to the test of level of inclusion.

Classroom Setting. Although classroom setting was operationalized as an 11-category variable, we conducted analyses of classroom setting regarding only five categories: hall, library, other, general education classroom, and special education classroom. The additional six categories were not used because participants were never coded in these settings. Table 3 shows that level of access did not change across 60 repeated cycles, $F(1,18.3)=$ $3.13, p=.09$. There was a significant effect of classroom setting on access to the curriculum, $F(4,159)=4.58, p<.01, R^{2}{ }_{1}=0.16$. Follow-up mean difference tests reported in Table 4 indicated that participants had a greater amount of curriculum access in the library, a general education classroom, and the special education classroom than in an "other" setting, library vs. other: $t(199)=3.85$, adj $-p<0.01, \delta=1.22$; general ed- ucation classroom vs. other: $t(111)=3.40$, adj- $p=$ $0.01, \delta=0.98$; special education classroom vs. other: $t(1103)=3.27, \operatorname{adj}-p=0.01, \delta=0.66$. However, no significant differences in curriculum access were detected between participants in the hallway, the library, the general education classroom setting, or the special education classroom setting.

Instructional Grouping, Physical Arrangement, and Classroom Setting. We also determined the collective impact of instructional grouping, physical classroom arrangements, and classroom setting conditions in predicting higher levels of access. Results in Table 5 suggest that as expected, level of access did not change across the 60 repeated cycles, $F(1,18.3)=2.34, p=.14$. As was shown in the previous analyses, there was a significant effect of classroom setting, $F(4,119)=11.48, p<0.01$, 
Estimated Means Access and Mean Difference in Access Follow-Up Test Results for Significant Main Effects

\begin{tabular}{|c|c|c|c|c|c|c|}
\hline & Estimated Means & & Follow & $U_{p}$ Test $\mathrm{p}-$ Valu & & \\
\hline Level of Inclusion & - & High & Medium & Low & & \\
\hline High inclusion & 3.99 & - & & & & \\
\hline Medium inclusion & 3.89 & 0.98 & - & & & \\
\hline Low inclusion & 1.23 & $<0.01$ & $<0.01$ & - & & \\
\hline \multicolumn{7}{|l|}{ Instructional Grouping } \\
\hline Independent & 3.09 & & & & & \\
\hline No instruction & 2.80 & & & & & \\
\hline One-on-one & 3.08 & & & & & \\
\hline Small group & 3.02 & & & & & \\
\hline Whole class & 3.10 & & & & & \\
\hline Physical Arrangement & & Divided & Entire & Individual & & \\
\hline Divided group & 3.22 & - & & & & \\
\hline Entire group & 3.43 & 0.32 & - & & & \\
\hline Individual & 2.26 & $<0.01$ & $<0.01$ & - & & \\
\hline Classroom Setting & & Hall & Library & Other & Regular & Spec. \\
\hline Hall & 2.35 & - & & & & \\
\hline Library & 3.77 & 0.06 & - & & & \\
\hline Other & 1.29 & 0.30 & $<0.01$ & - & & \\
\hline General ed classroom & 3.29 & 0.27 & 0.57 & $<0.01$ & - & \\
\hline Special ed classroom & 2.64 & 0.95 & 0.20 & 0.01 & 0.61 & - \\
\hline
\end{tabular}

and a significant effect of physical arrangement, $F(2,696)=36.60, p<0.01$. When classroom setting and physical arrangement were taken into account, there was a significant effect of instructional grouping as well, $F(4,1114)=5.26$, $p<0.01$. Altogether, instructional grouping, physical classroom arrangements, and classroom setting conditions accounted for $52 \%$ of the within-student variance and level of inclusion accounts for $67 \%$ of the between-student variance.

Follow-up comparisons suggested that when considering the effect of classroom setting and controlling for physical arrangement and instructional grouping, access to the curriculum was correlated most highly (and statistically indistinguishable) in the library and general education education classroom settings. The next highest access levels were observed in the hallway and special education setting (also indistinguishable from one another). The "other" setting again had the lowest levels of access to the curriculum. Setting means and Tukey-adjusted $p$-values are reported in Table 5 .
... when considering the effect of classroom setting and controlling for physical arrangement and instructional grouping, access to the curriculum was correlated most highly (and statistically indistinguishable) in the library and general education classroom settings.

When classroom setting and instructional grouping were accounted for, students in an entire group arrangement had more access to the general education curriculum than students in a divided group arrangement or an individual arrangement. Students in a divided arrangement also had more access than students in an individual arrangement, as reported in Table 5.

When instructional grouping was considered by itself as a predictor of access, no grouping differences were found (see Table 4). However, when classroom setting and physical arrangement were controlled for in this analysis (see Table 5), partic- 
TABLE 5

Multilevel Modeling Results for Research Question 3: Predicting Access

\begin{tabular}{|c|c|c|c|c|c|c|}
\hline Fixed Effects & Num DF & Den $D F$ & $\mathrm{~F}$ & Sig. & & \\
\hline Wave & 1 & 18.3 & 2.34 & 0.14 & & \\
\hline Setting & 4 & 119.0 & 11.48 & $<0.01$ & & \\
\hline Arrangement & 2 & 696.0 & 36.60 & $<0.01$ & & \\
\hline Grouping & 4 & 1114.0 & 5.26 & $<0.01$ & & \\
\hline Random Effects & & & $\begin{array}{l}\text { Variance } \\
\text { Estimate }\end{array}$ & Sig. & & \\
\hline $\begin{array}{l}\sigma_{\text {mnt }}^{2} \\
\sigma_{\text {Wave }}^{2} \\
\sigma_{\text {lnt }}^{2} \text { Wave } \\
\text { Residual }\end{array}$ & & & $\begin{array}{r}1.162 \\
0.001 \\
-0.027 \\
1.188\end{array}$ & $\begin{array}{r}<0.01 \\
<0.01 \\
0.02 \\
<0.01\end{array}$ & & \\
\hline Mean Difference Tests & Estimated Means & & & $w$-Up Test $\mathrm{p}^{-1}$ & Values & \\
\hline Classroom Setting & & Hall & Library & Other & General Ed. & Spec. Ed. \\
\hline Hall & 2.34 & - & & & & \\
\hline Library & 3.62 & 0.01 & - & & & \\
\hline Other & 0.28 & $<0.01$ & $<0.01$ & - & & \\
\hline General ed classroom & 3.43 & 0.01 & 0.55 & $<0.01$ & - & \\
\hline Special ed classroom & 1.87 & 0.22 & $<0.01$ & $<0.01$ & $<0.01$ & - \\
\hline Physical Arrangement & & Divided & Entire & Individual & & \\
\hline Divided group & 2.62 & - & & & & \\
\hline Entire group & 3.10 & $<0.01$ & - & & & \\
\hline Individual & 1.21 & $<0.01$ & $<0.01$ & - & & \\
\hline Instructional Grouping & & Indep. & No Inst & One & Small & Whole \\
\hline Independent & 2.55 & - & & & & \\
\hline No instruction & 2.06 & 0.45 & - & & & \\
\hline One-on-one & 2.63 & 0.98 & 0.27 & - & & \\
\hline Small group & 2.24 & 0.30 & 0.98 & 0.25 & - & \\
\hline Whole class & 2.07 & $<0.01$ & 1.00 & $<0.01$ & 0.81 & - \\
\hline
\end{tabular}

ipants grouped one-on-one and independently were found to have significantly greater access than students in a whole class grouping, one-onone vs. whole class: $t(1120)=3.60$, adj- $p<0.01$, $\delta=0.36$; independent vs. whole class: $t(1112)=$ 3.97 , $\operatorname{adj}-p<0.00, \delta=0.31$; one-on-one vs. independent: $t(1119)=0.59$, adj $-p=.98, \delta=0.05$.

\section{DISCUSSION}

This study examined the degree to which students with intellectual or developmental disabilities were involved in tasks related to the general education curriculum, or were provided supports to better enable them to be involved with that curriculum, and examined classroom ecological and setting factors that were related to student access to the general education curriculum.

With regard to the first research question (i.e., to what degree students with intellectual and developmental disabilities had access to the general education curriculum), similar to findings from Wehmeyer et al. (2003), results from this study appear at first to be encouraging. Students with intellectual and developmental disabilities worked on grade level standards $(60 \%$ of intervals) more than three times the frequency of intervals in which they worked on a standard linked to just any grade ( $20 \%$ of intervals), or on IEP 
objectives (23\% of objectives). Clear differences existed, however, in the frequency of intervals in which students worked on grade level standards and IEP objectives as a function of the student's inclusion status. Participants in the high inclusion group were working on a general education standard in $98 \%$ of intervals, with students working on an activity linked to a grade level standard in $83 \%$ of those intervals. Students in the medium inclusion group were observed working on a standard linked to the general education curriculum $96 \%$ of intervals, $93 \%$ of those linked to a grade level standard. Students in the low inclusion group, however, were observed working on an activity linked to any general education standard only $46 \%$ of intervals; there was not a single interval in which a student in the low inclusion group was observed working on a grade level standard.

An opposite trend for working on IEP goals emerged from the data. Students in the high inclusion group were working on IEP goals $10 \%$ of intervals, and students in the medium inclusion group were involved in activities linked to IEP goals $6 \%$ of intervals. Students in the low inclusion group, however, were working on activities related to IEP goals in almost $58 \%$ of intervals. This is consistent with observations from Wehmeyer et al. (2003) and suggests that the IEPs of students with intellectual and developmental disabilities do not, to this point, align well with the general education curriculum. These differences were not a function of student levels of ability, as the inclusion groups did not differ by overall or learning support needs ratings.

The use of accommodations and curriculum modifications (e.g., augmentations and adaptations) also mirrored what Wehmeyer et al. (2003) found. In both studies, students were most often provided accommodations, followed by adaptations. Because the presence of paraprofessionals and peer support was coded as an accommodation, the finding that $67 \%$ of intervals recorded included an accommodation is not surprising. The presence of a paraprofessional can be either positive or negative with regard to student access to the general education curriculum (Giangreco, 2003). If that paraprofessional is providing needed supports for students to work on grade level standards, it is most likely positive. If that person is working one-on-one with the student on content other than that on which the rest of the class is working, it is not. At least for those students served in general education classrooms, the fact that they were working almost exclusively on standards-based activities would suggest that paraprofessionals were providing those needed supports.

On average, we observed adaptations in only $18 \%$ of intervals, across all classroom settings, ranging from $18 \%$ of intervals for students in the high inclusion group, to $12 \%$ for students in the medium group, to $24 \%$ for students in the low inclusion group. Frequently, students were working on tasks in which the amount of work was reduced, reading level was lowered, or picture representations of key words and concepts were included. Two students, both observed in the same self-contained classroom, worked on social studies worksheets that targeted lower grade level standards that were adapted with BoardMaker ${ }^{\mathrm{TM}}$ 5.5.10 picture symbols (i.e., nonprint content) for the majority of observations. Observations of these two students contributed to the majority of adaptations observed for the low inclusion group.

We did not observe any occurrences of curriculum augmentations for any group. This is consistent with findings from Wehmeyer et al. (2003) and suggests that students with intellectual and developmental disabilities are often not provided the opportunity to learn and apply learning-to-learn or self-regulation strategies that could enable them to better interact with the general education curriculum. Given that it is important for students with learning disabilities to achieve such access, the lack of such augmentations for students with intellectual and developmental disabilities is all the more striking.

Students in the high and medium inclusion groups had higher mean access scores than students in the low inclusion group (see Table 4). This reflects, undoubtedly, the disproportionate frequency of activities linked to the general education curriculum observed for students in general education settings. The clear suggestion from these data is that students who are included in the general classroom have greater access to the general education curriculum.

Analyses for the second research question (i.e., correlation among classroom setting and 
ecological variables), examined this directly. MLM analysis indicated that inclusion status was a significant predictor of access to the general education curriculum; over a 60 -cycle observation period, high and medium inclusion status was related to higher access scores. In other words, being educated with nondisabled peers more than half of the instructional day (i.e., medium and high inclusion groups) was predictive of greater access to the general education curriculum.

MLM analysis of instructional grouping data (i.e., whole class, small group, one-on-one, independent, and no instruction variables) indicated no significant relationships. The physical arrangement or location of students in the classroom in relationship to each other, however, did predict student access. MLM analysis found a significant effect of physical arrangement on access, and significant differences between entire group and individual group physical classroom arrangements and between divided group and individual group arrangements. These findings suggest that students educated in divided and entire group physi$\mathrm{cal}$ arrangements had greater access to the general education curriculum than students educated in individual physical arrangements (e.g., seated in study carrels or seated away from all other students in classroom). Although this finding has not been identified in other research, it seems logical that physical arrangement would be related to the degree to which students have access to the general education curriculum. Both divided group and entire group conditions situate students, including students with disabilities, in close proximity to peers.

MLM analysis for classroom setting found that, among the coded five settings, there was a significant effect of classroom setting on access to the general education curriculum. Mean difference tests indicated that the library, general education, and special education classroom settings increased access to the general education curriculum more than "other" settings. This finding may suggest simply that structured learning environments, whether they are the library, general education classroom or special education classroom, are places in which activities focus more on grade level standards in comparison to the settings such as the hall and other settings.
The analysis for the third research question examined the impact of instructional grouping, physical arrangement, and classroom setting simultaneously. This analysis found (as was the case when examined alone) that educating students with intellectual and developmental disabilities in general education classrooms with nondisabled peers contributed to access to the general education curriculum. Second, the analysis confirmed that students with disabilities who are seated in the same physical arrangement with at least some of their peers have greater access to the general education curriculum.

... students educated in divided and entire
group physical arrangements had greater
access to the general education curriculum
than students educated in individual
physical arrangements.

Moreover, this analysis found that students who worked exclusively with a teacher, paraprofessional, or peer tutor in a one-on-one situation had greater access to the general education curriculum. Similarly, study participants observed working independently (e.g., independent seat work) had greater access. This finding is similar to research showing that small group and one-onone instruction are more effective means for delivering instruction than whole group instruction. However, the finding that independent instruction promoted access was not expected. This suggests that students with intellectual and developmental disabilities are capable of managing their own learning when working on content related to the general education curriculum.

\section{LIMITATIONS OF STUDY}

There are several limitations that warrant consideration. First, the sample size was relatively small $(n=19)$ and thus presents problems for generalization. Given, however, the congruence between our findings and those of Wehmeyer et al. (2003), we believe that these findings are not outside the norm as they relate to the issue of access to the general education curriculum for students with intellectual disabilities. Second, several students in 
the study were taught by the same teacher during their respective observations. Thus, it is likely that certain students were treated the same way-what appear to be classroom setting effects might be teacher effects. Again, given the congruence between this study's findings and the Wehmeyer et al. (2003), this doesn't seem overly likely, but should be considered. Third, the equation developed to create an access score was based on the researchers' opinions, and was not validated by external researchers. It was, however, based upon a theoretical framework developed to promote access for students with severe disabilities (Wehmeyer, 2003) and preliminary research conducted within the framework of this model (Wehmeyer et al., 2003). Fourth, although we conducted multiple observations in part to try to ensure that the lessons observed were typical of the students' activities, we could not ensure that this was the case. It seems likely so, however, at least in part due to the high number of minutes observed. Fifth, by creating a categorical variable out of a continuous variable (e.g., percentage of school day spent in general education classroom settings) we lost some variability. Finally, we should note that findings are correlational in nature and causality should not be inferred.

\section{IMPLICATIONS FOR PRACTICE}

Understanding the degree to which students with intellectual and developmental disabilities have access to the general education curriculum is the first step to meeting the challenge presented by IDEA access mandates. Idencifying instructional and ecological variables that predict such access is also important. This study, along with findings from Wehmeyer et al. (2003), suggests that students with intellectual and developmental disabilities are more likely to have access to the general education curriculum if they are educated in the general education classroom. These two studies also suggested that instruction in special education classroom setrings tends to focus more on IEP objectives that appear to be, at least at this time, disconnected from the general education curriculum.

Inclusion in the general classroom is, however, a necessary but not sufficient step to pro- moting access. To fulfill the intent of IDEA, supplemental aids and services that enhance student access need to be provided. This study examined several of these, including the provision of accommodations, curriculum modifications, and classroom ecological variables. Accommodations were most frequently observed, but only during about half the time instruction was occurring. The primary type of accommodation was the use of paraprofessional support, and, to a lesser degree, peer support. There is a need to consider a broader array of accommodations, particularly, perhaps, assistive technology. Both this study and Wehmeyer et al. (2003) found that curriculum adaptations were only occasionally provided and that curriculum augmentations were never implemented. There is a convincing literature base that indicates students with intellectual and developmental disabilities can learn strategies that could enable them to better access the curriculum, such as self-instruction or self-monitoring strategies.

This study suggests three important practices pertaining to classroom ecological variables for promoting access. First, our data and that of Wehmeyer et al (2003) suggest that it is important to educate students with developmental and intellectual disabilities with their nondisabled peers so that they have access to the general education curriculum. Second, when configuring a classroom seating arrangement, educators should place some if not all students in the same seating pattern (e.g., all in a row, all in a circle, etc.). Third, it appears to be important to provide instruction in a one-on-one situation between students with a disability and a teacher, paraprofessional or peer tutor, or to provide time for students to work independently.

\section{REFERENCES}

Agran, M., Alper, S., \& Wehmeyer, M. (2002). Access to the general curriculum for students with significant disabilities: What it means to teachers. Education and Training in Mental Retardation and Developmental Disabilities, 37, 123-133.

Baker, S., Gersten, R., \& Scanlon, D. (2002). Procedural facilitators and cognitive strategies: Tools for unraveling the mysteries of comprehension and the writing process and for providing meaningful access to the gen- 
eral curriculum. Learning Disabilities: Research and Practice, 17, 65-77.

Bashinski, S. M., \& Wehmeyer, M. L. (2002). Access CISSAR (version 1.0) [Computer software]. Lawrence, KS: University of Kansas.

Bulgren, J. A., \& Carta, J. J. (1993). Examining the instructional contexts of students with learning disabilities. Exceptional Children, 59, 182-191.

Carta, J. J., Greenwood, C. R., Schulte, D., ArreagaMayer, C., \& Terry, B. (1988). Code for instructional structure and student academic response: Mainstream version (MS-CISSAR). Kansas City, KS: Juniper Gardens Children's Project, Bureau of Child Research, University of Kansas.

Cobb-Morocco, C. (2001). Teaching for understanding with students with disabilities: New directions for research on access to the general education curriculum. Learning Disability Quarterly, 24, 5-11.

De La Paz, S., \& MacArthur, C. (2003). Knowing the how and why of history: Expectations for secondary students with and without learning disabilities. Learning Disability Quarterly, 26, 142-154.

Deshler, D., Shumaker, J., Bulgren, J., Lenz, K., Jantzen, J., Adams, G., et al. (2001). Making learning easier: Connecting new knowledge to things students already know. TEACHING Exceptional Children, 33(4), $82-85$.

Dymond, S. K., \& Orelove, F. P. (2001). What constitutes an effective curriculum for students with severe disabilities? Exceptionality, 9, 109-122.

Ford, A., Davern, L., \& Schnorr, R. (2001). Learners with significant disabilities: Curricular relevance in an era of standards-based reform. Remedial and Special Education, 22, 214-222.

Giangreco, M. F., (2003). Working with paraprofessionals. Educational Leadership, 1(2), 50-53.

Graham, S., \& Harris, K. (2005). Writing better: Effective strategies for teaching students with learning difficulties. Baltimore: Paul H. Brookes.

Greenwood, C., R., Arreaga-Mayer, C., \& Carta, J. J. (1994). Identification and translation of effective, teacher-developed instructional procedures for general practice. Remedial and Special Education, 15, 140-151.

Greenwood, C. R., Carta, J. J., Arreaga-Mayer, C., \& Rager, A. (1991). The behavior analyst consulting model: Identifying and validating naturally effective instructional procedures. Journal of Behavioral Education, 1(4), 165-191.

Greenwood, C. R., Carta, J. J., Kamps, D., \& ArreagaMayer, C. (1990). Ecobehavioral analysis of classroom instruction. In S. Schroeder (Ed.), Ecobehavioral analy- sis and developmental disabilities (pp. 33-63). Baltimore: Paul H. Brookes.

Greenwood, C. R., Carta, J. J., Kamps, D., Delquadri, J., Terry, B., Finney, R., et al. (1997). Ecobehavioral assessment systems software: (EBASS). Practitioner's Manual (Version 3.0). Kansas City, KS: Juniper Gardens Children's Project, University of Kansas.

Hartmann, D. P., \& Woods, D. D. (1982). Observational methods. In A. S. Bellack, M. Hersen, \& A. E. Kazdin (Eds.), International handbook of behavior therapy (pp. 109-138). New York: Plenum.

Hunt, P., Farron-Davis, F., Beckstead, S., Curtis, D., \& Goetz, L. (1994). Evaluating the effects of placement of students with severe disabilities in general education versus special classes. Journal of the Association for Persons with Severe Handicaps, 19, 200-214.

Individuals With Disabilities Education Improvement Act of 2004, 20 U.S.C. $\$ 1400$ et seq. (2004).

Janney, R., \& Snell, M. (2004). Teachers' guides to inclusive practices: Modifying schoolwork (2nd ed.). Baltimore: Paul H. Brookes.

Jitendra, A. K., Edwards, L., Chourka, C. M., \& Treadway, P. S. (2002). A collaborative approach to planning in the content areas for students with learning disabilities: Accessing the general curriculum. Learning Disabilities Research and Practice, 17, 252-267.

Kamps, D., Greenwood, C. R., \& Leonard, B. (1991). Ecobehavioral assessment in classrooms serving children with autism and developmental disabilities. In R. Prinz (Ed.), Advances in behavior assessment of children and families (pp. 203-239). New York: Kingsley.

Kamps, D. M, Leonard, B. R., Dugan, E. P., Boland, B., \& Greenwood, C. R. (1991). The use of ecobehavioral assessment to identify naturally occurring effective procedures in classrooms serving children with autism and other developmental disabilities. Journal of Special Education, 1, 367-397.

Lee, S. H., Amos, B. A., Gragoudas, S., Lee, Y., Shogren, K. A., Theoharis, R., et al. (2006). Curriculum augmentation and adaptation strategies to promote access to the general curriculum for students with intellectual and developmental disabilities. Education and Training in Developmental Disabilities, 41, 199-212.

Logan, K., Bakeman, R., \& Keefe, E. (1997). Effects of instructional variables on engaged behavior of students with disabilities in general education classroom. Exceptional Children, 64, 481-497.

Logan, K., \& Keefe, E. (1997). A comparison of instructional context, teacher behavior, and engaged behavior for students with severe disabilities in general 
education and self-contained elementary classrooms. Journal of the Association for Persons with Severe Disabilities, 22, 16-27.

Moerbeek, M., Van Breukelen, G. J. P., Berger, M. P. F., \& Ausems, M. (2003). Optimal sample sizes in experimental designs with individuals nested within clusters. Understanding Statistics, 2, 151-175.

Nolet, V., \& McLaughlin, M. (2000) Accessing the general curriculum: Including students with disabilities in standards-based reform. Thousand Oaks, CA: Corwin Press.

Pressley, M. (2005). Reading instruction that works: The case for balanced teaching (3rd ed.). New York: Guilford Press.

Pugach, M. C., \& Warger, C. L. (2001). Curriculum matters: Raising expectations for students with disabilities. Remedial and Special Education, 22, 194-196.

Raudenbush, S. W., \& Bryk, A. S. (2002). Hierarchical linear models: Applications and data analysis methods (2nd ed.). Thousand Oaks, CA: Sage.

Raudenbush, S. W., Spybrook, J., Liu, X., \& Congdon, R. (2005). Optimal design for longitudinal and multilevel research: Documentation for the "Optimal Design" software. Unpublished manuscript.

Satterthwaite, F. E. (1946). An approximate distribution of estimates of variance components. Biometric Bulletin, 2, 110-114.

Sax, G. (1997). Principles of educational measurement and psychological measurement and evaluation (4th ed). Belmont, CA: Wadsworth Publishing.

Snijders, T., \& Bosker, R. (1999). Multilevel analysis: An introduction to basic and advanced multilevel modeling. London: Sage.

Swanson, H., \& Deshler, D. (2003). Instructing adolescents with learning disabilities: Converting a metaanalysis to practice. Journal of Learning Disabilities, 36(2), 124-135.

Swanson, H., \& Hoskyn, M. (2001). Instructing adolescents with learning disabilities: A component and composite analysis. Learning Disabilities Research and Practice, 16, 109-119.

Thurlow, M., Ysseldyke, J., Graden, J., \& Algozzine, B. (1983). What's "special" about the special education resource room for learning disabled students? Learning Disability Quarterly, 6, 283-288.

Turnbull, R., Turnbull, A., \& Wehmeyer, M. L. (2007). Exceptional lives: Special education in today's schools (5th ed.). Columbus, OH: Merrill/Prentice Hall.

Wehmeyer, M. L. (2003). Defining mental retardation and ensuring access to the general curriculum. Education and Training in Developmental Disabilities, 38, 270-281.

Wehmeyer, M. L., Lance, G. D., \& Bashinski, S. (2002). Promoting access to the general curriculum for students with mental retardation: A multi-level model. Education and Training in Mental Retardation and Developmental Disabilities, 37, 223-234.

Wehmeyer, M. L., Lattin, D., Lapp-Rincker, G., \& Agran, M. (2003). Access to the general curriculum of middle school students with mental retardation: An observational study. Remedial and Special Education, 24(5), 262-272.

\section{ABOUT THE AUTHORS}

JANE H. SOUKuP (CEC KS Federation), Research Assistant Professor, Beach Center on Disability; MICHAEL L. WEHMEYER (CEC KS Federation), Professor of Special Education, Director of Center on Developmental Disabilities, and Senior Scientist, Beach Center on Disability; and SUSAN M. BASHINSKI (CEC KS Federation), Research Assistant Professor, Beach Center on Disability, University of Kansas. JAMES A. BovaIRD, Assistant Professor of Educational Psychology, Department of Educational Psychology, University of Nebraska-Lincoln.

Correspondence concerning this article should be addressed to Jane H. Soukup, P.O. Box 71755 , Phoenix, AZ 85050 (e-mail: jhelen@ku.edu).

Funding for this study was provided by Grant \#H324D000025 from the U.S. Department of Education, Office of Special Education Programs, awarded to The University of Kansas. Endorsement by the Federal Government should not, however, be assumed.

Manuscript received June 2005; accepted December 2006 . 
Copyright of Exceptional Children is the property of Council for Exceptional Children and its content may not be copied or emailed to multiple sites or posted to a listserv without the copyright holder's express written permission. However, users may print, download, or email articles for individual use. 